but emphasis was placed, by the working party, on the importance of correct diagnosis before any treatment is undertaken.

Another assignment he clearly enjoyed was a survey of health care in Guernsey.

His last chapter, entitled Questions without Answers, deals with ethical and medical practice. He concludes that doctors must maintain good standards of medical practice. Research must be based on sound ethical practice. In no sphere is this currently more important than in the current discussion of in vitro fertilisation and all that results from the new techniques of human reproduction, and Sir Douglas must be a valued member of the Voluntary Licensing Authority set up under the chairmanship of Dame Mary Donaldson by the Royal College of Obstetricians and Gynaecologists and the Medical Research Council. The deliberations of this authority will be invaluable when legislation on these difficult and contentious matters is debated in Parliament.

This is a fascinating and eminently readable account of a life spent in the service of medicine in its widest context. Douglas Black is never pompous and his writing is admirably economical of words. Like a field marshal's baton it should be in the knapsack of every medical student and young doctor, while those of more mature years will profit as I have, by the privilege of reading it and of knowing a truly great physician.

DAME JOSEPHINE BARNES Consulting Obstetrician and Gynaecologist

Charing Cross Hospital and Elizabeth Garrett Anderson Hospital 8 Aubrey Walk London W8

\section{Setting Limits: Medical Goals in an Aging Society}

Daniel Callahan, 256 pages, New York, $\$ 18.95$, Simon and Shuster, 1987
The author of this important book is director of the Hastings Center for the study of Medical Ethics in the United States. He has written on medical ethical topics such as abortion and 'medicated survival'.

In this book he addresses the issue of when and in what circumstances it is suitable to withhold the full panoply of modern medical technology from sick old people and comes down firmly in favour of applying only measures for relief of suffering and preservation of dignity for those who have become aged and who have led long and full lives.

He discusses in detail the arrogant assumptions which underlie the use of medical technology to prolong life in almost any circumstances and points out that when applied to very old people this destroys the very meaning of old age as a time of reflection and of help to younger generations which is characterised by an acceptance of death as a natural and desirable event when its time has come.

There is a useful discussion of the rights and obligations of generations within society and Burke is quoted: 'Society is a partnership not only between those who are living, but between those who are living, those who are dead and those who are to be born'. He maintains that society owes more to the young than to the old: 1) since the former have not asked to be born, and 2) since the old have in any case led full and long lives and may thus be prepared to leave this world.

\section{Dignity}

Modern medicine has enabled us to avoid or postpone death in a remarkable fashion, but its indiscriminate use in old age is to be deprecated since it not only squanders vast resources (hence not available for younger patients) but also distorts the true meaning and dignity of old age.

It is emphasised that while extraordinary measures directed solely at life prolongation are to be avoided in old age, it is essential that suffering must be relieved, expert nursing care must be freely available and family and other carers must always receive the fullest help and support. A plea is made for treatment of the patient as an individual, which is much more important than treatment of his or her organs. Excessive use of technology is cruel where 'life has become a blight rather than a blessing' and the author describes this use 'not, as some would have it, respect for age but an idolatrous enslavement to technology'.

At an early stage in this book it is stated that the author advocates withholding of medical technology (for life prolongation) above a certain age (late 70's, early 80's) and I became fascinated to find out how he was going to sustain this suggestion. However, on page 184 he retreats by stating that for the 'physically vigorous old person' all levels of care are appropriate. In other words, it is not age but 'physical vigour' which must determine our response. Unfortunately we are not in a good position to judge this since it is dependent upon reserve function, and $\Theta$ we have only imperfect ways of $\frac{\mathbb{D}}{D}$ measuring this. Thus we fall back upon 'clinical judgement' with all its imprecisions and deficiencies.

\section{Perspicacity}

It is of more than passing interest the the author compares the British syste very favourably with the American. has been possible in the UK 'to break the monopoly of high-technology medicine and the endless struggle against aging and death that has been its most willing partner'. With remarkable perspicacity, the author warns us against our current trend towards 'recreation of a private health care system' which steers medicine in the US direction.

I would have dearly liked to comment upon the sections which deal with euthanasia (easily dismissed) and the withholding of antibiotics, fluid and food (competently supported) but space does not permit.

Doctors and nurses should read this $I$ book, as should thinking laymen and politicians.

PROF J WILLIAMSON N 14 Ann Street 요 Edinburgh $\omega$ EH4 1PF 